\title{
Comparison of BMI and Waist Circumference with the Risk of Uncontrolled Hypertension Among Adult Population in Bogor, Indonesia (Longitudinal Data Analysis Using Generalized Estimating Equations)
}

\author{
Dewi Kristanti $^{1^{*}}$, Woro Riyadina ${ }^{1}$ \\ ${ }^{I}$ National Institute of Health Research and Development, Ministry of Health, Jakarta, Indonesia \\ *Corresponding author.Email: dewikris@litbang.depkes.go.id
}

\begin{abstract}
Uncontrolled hypertension increases the risk of cardiovascular morbidity and mortality. Longitudinal studies comparing the effect of BMI and waist circumference with the prevalence of uncontrolled hypertension is limited. This study aims to compare the effects of obesity using BMI and waist circumference criteria with uncontrolled hypertension. Longitudinal data from the Indonesia-Cohort Bogor Study in $2011-2018$ was used. The population was adult aged 25 - 65 years who became subjects of the Indonesia-Cohort Bogor Study in 2011 and 2012. The sample was subjects with hypertension at the beginning of the study and have completed 6 years of follow-up period. The total of 481 subjects or 2,866 personyears were analysed using the Generalized Estimating Equations (GEE). The results showed that in the 6-years of follow-up period in all groups of subjects, the risk of uncontrolled hypertension was 1.621 times (95\% CI: $1.160-2.267)$ and 1.987 times (95\% CI: $1.450-2.722)$ in subjects who experienced overweight and obesity compared to subjects with normal BMI; and 1.437 times (95\% CI: $1.136-1,819)$ in subjects who experienced central obesity compared to subjects with normal waist circumference, adjusted by age, smoking behavior, natrium intake and year of follow-up. Based on the results of the analysis by gender, the risk of uncontrolled hypertension was higher in male group who experienced overweight, obese, or central obesity compared with female group. Obesity using BMI calculation was stronger predictor than central obesity using waist circumference for the risk of uncontrolled hypertension. The results of this study are expected to be used for improving intervention and controlling hypertension programs in Indonesia.
\end{abstract}

Keywords: uncontrolled hypertension, obesity, Indonesia cohort study, generalized estimating equation

\section{INTRODUCTION}

Hypertension is a health problem both at global and national levels because the incidence and complications are increasing from year to year. Based on WHO, in 2015, there was an increased blood pressure in 1.13 billion people worldwide when compared with 1975 data [1]. In the United States, approximately $29 \%$ or 75 million people experience hypertension [2]. While in Indonesia, according to the results of National Basic Health Research, the prevalence of hypertension was $25.8 \%$ in 2013 [3] and increased to $34.1 \%$ in 2018 [4].

Hypertension is one of the main risk factors for global death. Uncontrolled hypertension is proven to be positively and continuously associated with risk of stroke and coronary heart disease [1]. Compared with norm tension, patients with uncontrolled hypertension are at higher risk for experiencing death from all causes $(\mathrm{HR}=1.62,95 \% \mathrm{CI}$ $=1.35-1.95)$, death due to cardiovascular disease $(\mathrm{HR}=$ $2.23,95 \% \mathrm{CI}=1.66-2.99)$, death due to heart disease $(\mathrm{HR}=$ $2.19,95 \% \mathrm{CI}=1.57-3.05)$ and death due to cerebrovascular disease $(\mathrm{HR}=3.01,95 \% \mathrm{CI}=1.91-4.73)$ [5].

Globally, the number of people with uncontrolled hypertension rises from 600 million in 1980 to nearly 1 billion over 3 decades due to population growth and aging [1]. Proportion of uncontrolled hypertension in people who get anti-hypertension in developed countries amounting to approximately 50\% [6]. Whereas in Asia, based on the results of studies in Malaysia, obtained that $84.1 \%$ of subjects with hypertension had uncontrolled hypertension. And even in hypertensive subjects who have already taken medication, uncontrolled hypertension occurred in almost 
$70 \%$ of subjects [7]. In Indonesia, using data from Indonesia Family Life Survey (IFLS) 2007, Hussain et al. (2016) found that the prevalence of uncontrolled hypertension reached $91 \%$ [8].

Several factors can be the cause of uncontrolled hypertension. One of the factors that play a role in the occurrence of uncontrolled hypertension is obesity [8][9]. Based on research conducted by Sabaka (2017), an increased BMI of at least $1 \mathrm{~kg} / \mathrm{m}^{2}$ is associated with increased risk of uncontrolled hypertension in subject with obesity by 1.5 times in men and 1.4 times in women [10]. Riyadina (2007) found a correlation between weight gain with systolic blood pressure (SBP) and pressure diastolic blood (DBP) in the menopausal female population in the city of Bogor. After adjusting to the level of physical activity, an increase of $1 \mathrm{~kg}$ body weight increased SBP by $1.5 \mathrm{mmHg}, 2.7 \mathrm{mmHg}$ and $3.7 \mathrm{mmHg}$ respectively in the group with normotension, controlled hypertension, and uncontrolled hypertension. In addition, an increase of DBP by $0.9 \mathrm{mmHg}$ was described in the normotension group and by $1.3 \mathrm{mmHg}$ in both the controlled and uncontrolled hypertension groups [11].

Obesity and central obesity are well-known causes of hypertension and uncontrolled hypertension. But as we know, blood pressure is a condition that can change along with differences in measurement time and patient's condition. There is a limited data compared the effects of obesity using BMI and waist circumference criteria with the risk of uncontrolled hypertension that consider the variation or change of the status of uncontrolled hypertension. This study aims to obtain a prevalence of uncontrolled hypertension in 6 years of monitoring, and compare the effect of obesity using BMI and waist circumference criteria with the risk of uncontrolled hypertension using the longitudinal data analysis that can consider the change of the status of uncontrolled hypertension.

\section{METHOD}

This research is an observational study with a longitudinal study design of individuals who had experienced hypertension at the start of the study. Research using secondary data from The Cohort Study of NCD Risk Factors conducted by The National Institute of Health Research and Development, Ministry of Health from 2011 until 2018. The Cohort Study of NCD Risk Factors is a study to examine various risk factors associated with noncommunicable diseases, such as metabolic syndrome, Coronary Heart Disease (CHD), stroke and Diabetes Mellitus (DM). Located in the city of Bogor, this study has initial respondents of 5,000 with a $92 \%$ response rate in 6 years of follow-up. Baseline data is collected in 3 stages, namely in 2011, 2012 and 2015, whereas follow-up is carried out quarterly to measure blood pressure and anthropometry, yearly to measure blood pressure, anthropometry and behavioral risk factors, then every two years for the complete measurement [12].
The study population was adult population aged $25-65$ years who became subjects of the Cohort Study of NCD Risk Factors in 2011 and 2012, with total number of 4,918. Samples were respondents who had hypertension at the start of the study. Definition of hypertension based on guidelines from European Society of Cardiology/ European Society of Hypertension (ESC/ ESH), when systolic blood pressure $\geq$ 140 or diastolic blood pressure $\geq 90 \mathrm{mmHg}$ [13], or based on interviews that the subject was diagnosed with hypertension and took antihypertensive drugs. Subjects' blood pressure was measured every year to evaluate the status of their hypertension. Inclusion criteria were subjects who have had complete data on main variables in the study (blood pressure and BMI) and they were present in the follow-up period for up to 6 years. While the exclusion criteria were subjects who were pregnant or had noncommunicable diseases (DM, CHD, and/or stroke) at the start of the study.

Outcome of the study was uncontrolled hypertension using guidelines of ESC/ESH, when systolic blood pressure still reached $\geq 140 / 90 \mathrm{mmHg}$ in people with hypertension [13]. This outcome evaluated every year for 6 years. As the main exposure was obese, defined as an BMI of at least $25 \mathrm{~kg} / \mathrm{m}^{2}$; and central obesity, defined as a waist circumference at least $80 \mathrm{~cm}$ in female or $90 \mathrm{~cm}$ in male. Those criteria using WHO Criteria for Asia-Pacific Population. The outcome and main exposure were time-dependent variables which can be changed during follow-up period.

Some other risk factors determined in the study were sociodemographic and behavioral risk factors. Sociodemographic and behavioral information were collected by questionnaire which included questions on age, gender, marital status, educational level, working status, smoking habit (using Brinkman index), exercise, mental emotional status, and sodium intake. Blood pressure measurement was performed in the baseline, and every year during follow-up period. It was measured two or three times with a 5-minute pause on each examination using an AND digital tensimeter on the right arm and in a sitting position. While the anthropometric measurements were carried out through measurements of the height with fiberglass board, the weight with an AND digital, and the abdominal circumference used a measuring tape. BP and anthropometric measurements were carried out by trained nurses.

Data analysis were carried out with bivariate analysis using chi square to obtain subjects' characteristic of uncontrolled hypertension, and multivariate analysis using Generalized Estimating Equations (GEE) to assess the risk of uncontrolled hypertension with obese and central obesity, adjusted by other covariates that expressed as an adjusted odds ratio and its $95 \%$ CI. Confounder was determined from literature study and statistical tests.

In this GEE analysis, an autoregression (AR 1) was used as a working correlation structure, assumed that the prevalence 
of uncontrolled hypertension correlated with each other within subject, and the greatest correlation occurred by follow-up at a closer distance than a longer one. Uncontrolled hypertension as an outcome variable was a time-dependent variable, while risk factors consisted of time-dependent variables (BMI, waist circumference, brinkman index, exercise habit, mental emotional status, and sodium intake) and time-independent variables (sociodemographic characteristics at baseline such as gender, educational level, marital status, and working status).

\section{Ethical consideration}

The Cohort Study of NCD Risk Factor have properly reviewed and approved by Ethical committee of National Institute of Hearth Research and Development, Indonesia Ministry of Health. All requirements for consent for subjects were met and have approved before fieldwork could begin.

\section{RESULTS AND DISCUSSION}

\section{Flow chart of data collection}

The number of baseline data subjects that met the criteria was 4,918 people. From that number, as many as 3,198 were normotensive and 1,720 people had hypertension. In subjects with hypertension, there are 666 people who suffer from the NCD, 37 women were pregnant, and 93 subjects were lost to follow-up, and 443 subjects with uncompleted follow-up, so that the sample size for analysis was 481 people.

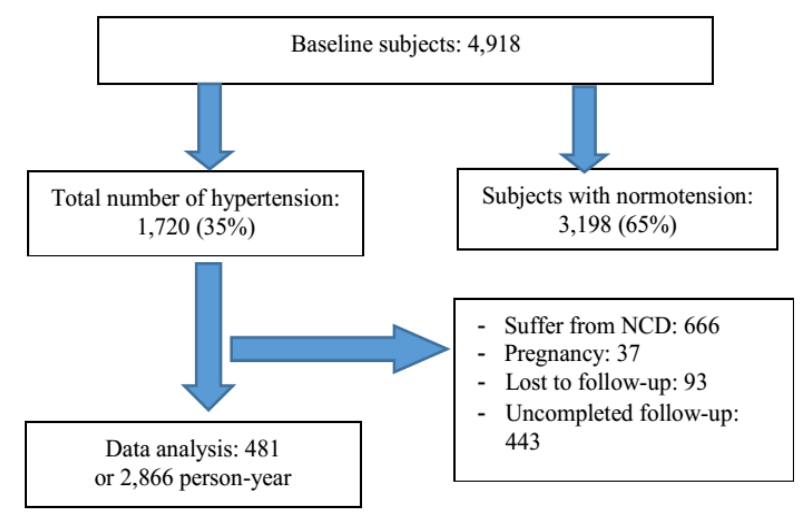

Figure 1. Flow cart of data collection

\section{Prevalence of uncontrolled hypertension}

The prevalence of uncontrolled hypertension varies from year to year. However, subjects with persistent uncontrolled hypertension that measured every-year within 6 years of follow up was $35 \%$. The description of the prevalence of uncontrolled hypertension by gender is shown in Figure 2. When compared with national research findings, for example, IFLS data for the year of 2007, these results are lower. In the national population in 2007, prevalence of uncontrolled hypertension was very high, reaching 91\% [8].

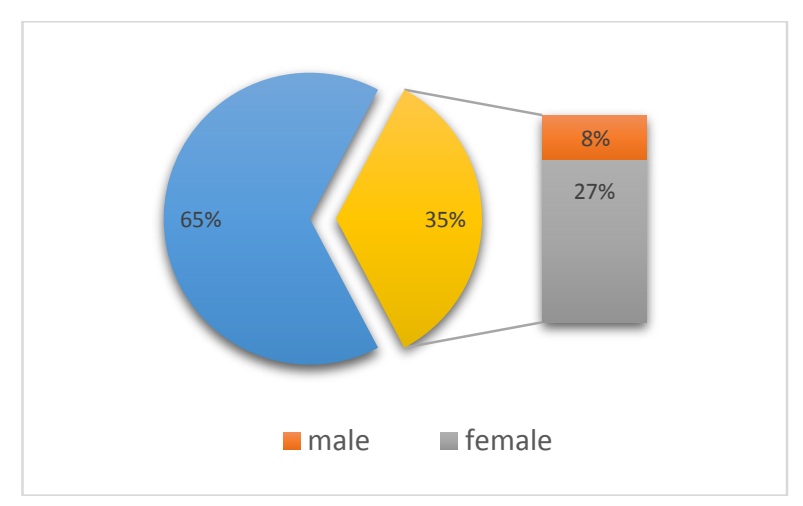

Figure 2. Prevalence of persistent uncontrolled hypertension by gender

\section{Subject Characteristics}

Subject characteristics in baseline study is shown in table 1. Based on sociodemographic characteristics, subjects with older age group, male, high educational level, working, and divorced had a higher proportion of persistent uncontrolled hypertension within 6 years of follow up.

These sociodemographic findings are quite different from other studies. Gee et al (2012) stated that age and gender are interrelated. They found that at a young age, men aged 20 to 44 years, are generally more at risk of developing uncontrolled hypertension, whereas in the 45-60 years' age group, women are more likely to have high blood pressure that is not controlled (OR, 2.4; $95 \%$ CI, 1.1-5.2) [13]. Regarding the relationship of educational level within lowincome countries, low education increases the risk of uncontrolled hypertension, but not in middle and high income countries [14]. 
Table 1. Subject characteristics based on sociodemographic, biological and behavioral factors

\begin{tabular}{|c|c|c|c|}
\hline \multirow{3}{*}{ Variables } & \multirow{3}{*}{ Category } & \multicolumn{2}{|c|}{ Uncontrolled HT } \\
\hline & & Yes $(n=166)$ & No $(n=315)$ \\
\hline & & $\%$ & $\%$ \\
\hline \multirow{3}{*}{ Age group } & $<45$ yo & 33.5 & 66.5 \\
\hline & $45-59$ уо & 34.1 & 65.9 \\
\hline & $\geq 60$ yo & 42.9 & 57.1 \\
\hline \multirow[t]{2}{*}{ Gender } & Male & 36.4 & 63.6 \\
\hline & Female & 34 & 66 \\
\hline \multirow[t]{3}{*}{ Educational level } & High & 37.5 & 62.5 \\
\hline & Middle & 31.7 & 68.3 \\
\hline & Low & 37.4 & 62.6 \\
\hline \multirow[t]{2}{*}{ Working status } & Not working & 33.6 & 66.4 \\
\hline & Working & 37.5 & 62.5 \\
\hline \multirow[t]{3}{*}{ Marital status } & Married & 34.1 & 65.9 \\
\hline & Not married & 36.8 & 63.2 \\
\hline & Divorced & 37.5 & 62.5 \\
\hline \multirow{4}{*}{ Body mass index } & Underweight & 16.7 & 83.3 \\
\hline & Normal & 20.2 & 79.8 \\
\hline & Overweight & 40.3 & 59.7 \\
\hline & Obese & 38 & 62 \\
\hline Waist & Normal & 31.3 & 68.8 \\
\hline circumference & Central obesity & 37 & 63 \\
\hline \multirow[t]{2}{*}{ Exercise habit } & Yes & 34.1 & 65.9 \\
\hline & No & 35.9 & 64.1 \\
\hline \multirow{6}{*}{$\begin{array}{l}\text { Mental emotional } \\
\text { disorder } \\
\text { Brinkman Index }\end{array}$} & No & 34.6 & 63.4 \\
\hline & Yes & 34.3 & 65.7 \\
\hline & Never smoker & 36.5 & 63.5 \\
\hline & Light smoker & 26.9 & 73.1 \\
\hline & $\begin{array}{l}\text { Moderate } \\
\text { smoker }\end{array}$ & 36 & 64 \\
\hline & Heavy smoker & 40 & 60 \\
\hline \multirow[t]{2}{*}{ Sodium intake } & Normal & 31.1 & 68.9 \\
\hline & High & 38.9 & 61.1 \\
\hline
\end{tabular}

Based on nutritional status, more than $50 \%$ of subjects were obese or have central obesity, and in both groups, the percentage of uncontrolled hypertension within those group higher than normal group. Based on other behavioral factors, subjects who didn't have regular exercise, heavy smoker, and high sodium intake also had a higher proportion of persistent uncontrolled hypertension within 6 years of follow up.

\section{Risk of uncontrolled hypertension and obesity}

The risk of uncontrolled hypertension and obesity were analysed using GEE with an autoregression/AR(1) as a working correlation structure. The results of the GEE analysis for the final model are presented in table 2 . The risk of uncontrolled hypertension was 1.621 times (95\% CI: $1.160-2.267)$ and 1.987 times (95\% CI: $1.450-2.722)$ in subjects who experienced overweight and obesity compared to subjects with normal BMI; and 1.437 times (95\% CI: $1.136-1,819)$ in subjects who experienced central obesity compared to subjects with normal waist circumference, adjusted by age, smoking behavior, natrium intake and year of follow-up. Based on the results of the analysis by gender, the risk of uncontrolled hypertension was higher in male group who experienced overweight, obese, or central obesity compared with female group.
Based on the results of studies about the effect of weight gain or increased BMI on the incidence of uncontrolled hypertension, it was found that in the group of young age (18-20 years), it was found that within one year of followup, the change of body weight and BMI in one year are associated with an increase of blood pressure both in men and women, regardless of their nutritional status at the baseline. It also found that the minimum weight gain of 5\% increased the risk of blood pressure in women [15].

Table 2. Multivariate analysis of the final model

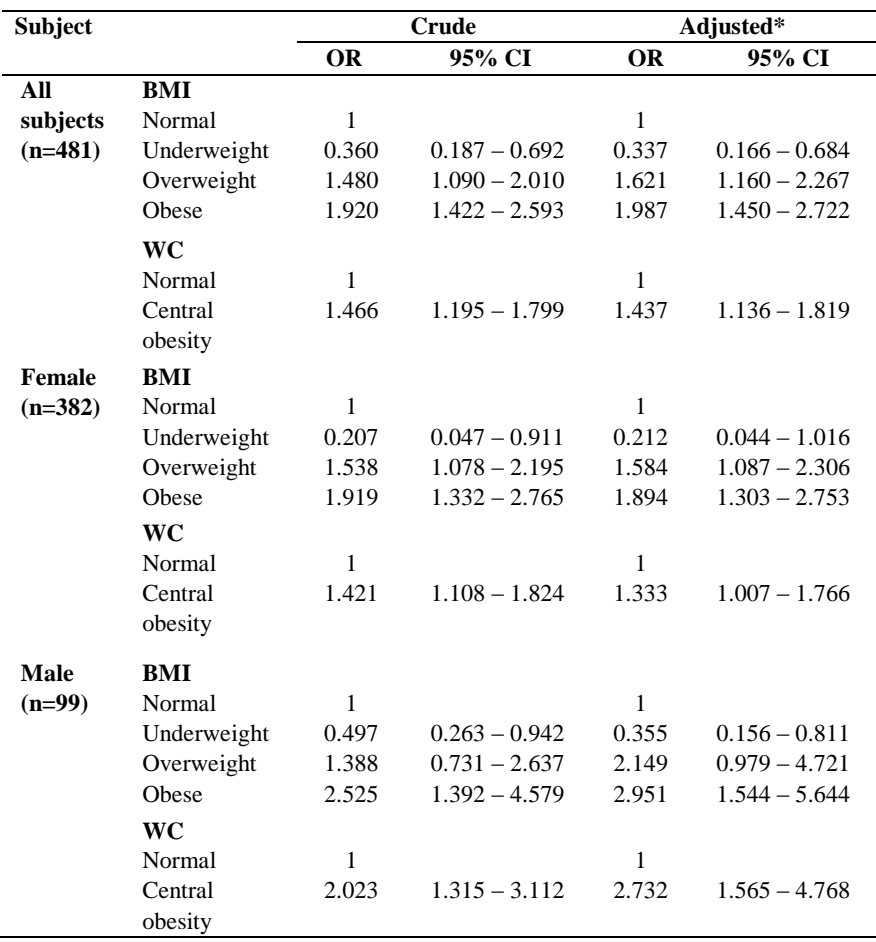

*adjusted by age, smoking status, sodium intake and years of follow-up

Uncontrolled hypertension is closely correlated with being overweight. A positive linear relationship between fat accumulation in the body and blood pressure has been proven, where the risk of hypertension is higher in people with obesity (WHO Western Pacific Region, 2000). Nutritional status that is associated with the incidence of uncontrolled hypertension is obesity [16]. Obesity increases the risk of uncontrolled hypertension 3 times [17]. Available linear relationship between body weight and blood pressure, that every $4.5 \mathrm{~kg}$ an increased body weight results in a $4 \mathrm{mmHg}$ increased SBP [10]. As for central obesity, based on research conducted in China, central obesity in women (abdominal circumference $\geq 80 \mathrm{~cm}$ ) increases the risk of uncontrolled hypertension [18]. Whereas in other studies in Sweden, it was found that among men, uncontrolled hypertension was associated with central obesity and increased the risk by 1.85 times [19]. Weight loss towards an ideal BMI is the best goal in lower blood pressure. Weight loss of $5 \mathrm{~kg}$ can reduce $4.4 \mathrm{mmHg}$ of SBP and $3.6 \mathrm{mmHg}$ of DBP, and increases the efficacy of antihypertensive drugs. Maintaining BMI and waist 
circumference within normal limits is recommended for healthy individuals to prevent hypertension, also in hypertensive patients to reduce blood pressure [20].

\section{Other risk factors}

Some of behavioral factors that influence the incidence of uncontrolled hypertension are lack of physical activity and smoking. These finding are similar with other studies. Regular exercise reduces blood pressure in individuals with hypertension. Borjesson et al in 2005 analysed scientific evidence of the effect of aerobic physical activity for the effect of reducing blood pressure in 27 randomized controlled studies in individuals with hypertension, and showed that moderate to high intensity aerobic activity reduced blood pressure by an average of $11 / 5 \mathrm{~mm} \mathrm{Hg}$. In addition, three randomized controlled trials (RCTs) on isometric (static) activity showed an equal decrease in blood pressure in hypertension; whereas dynamic resistance training might show smaller effects, as shown in the five available RCTs. Because of the high and increasing prevalence of hypertension in today's society, physical activity has a large role as a single treatment (if indicated) or additional treatment for hypertension [21].

As for smoking, the mechanism of uncontrolled hypertension due to chemicals that can damage the inner lining of the artery walls, making the arteries vulnerable to plaque accumulation. Based on the results of a study of 7,586 subjects who participated in the National Health and Nutrition Examination Survey 1999-2010, it was found that active smokers increased the risk of uncontrolled hypertension by 1.7 times in non-Hispanic black ethnicity, but the opposite results were found in the non-Hispanic white group [22].

\section{CONCLUSION}

This study found that the risk of uncontrolled hypertension was higher in subjects who experienced overweight and obesity compared to subjects with normal BMI; and in subjects who experienced central obesity compared to subjects with normal waist circumference, adjusted by age, smoking behavior, natrium intake and year of follow-up. Based on the results of the analysis by gender, the risk of uncontrolled hypertension was higher in male group who experienced overweight, obese, or central obesity compared with female group. These findings can be beneficial for government to make effective weight control programs to prevent and control hypertension.

\section{The contribution of authorship}

DK is the main contributor, responsible for data analysis and design of the manuscript. WR is a supporting contributor, responsible for manuscript revision and perform a final manuscript.

\section{REFERENCES}

[1] WHO. Raised blood pressure [Internet]. WHO. World Health Organization; 2015 [cited 2018 Oct 5]. Available from:

http://www.who.int/gho/ncd/risk_factors/blood_pressure_ prevalence_text/en/

[2] American Heart Association. Statistical Fact Sheet 2013 Update High Blood Pressure [Internet]. 2013 [cited 2018 Nov 28]. Available from: http://circ.ahajournals.org/lookup/doi/10.1161/CIR.0b013e 31828124ad

[3] Badan Penelitian dan Pengembangan Kesehatan. Riset Kesehatan Dasar Riskesdas 2013 [Internet]. Jakarta: Departemen Kesehatan Republik Indonesia. 2013. Available from: http://www.academia.edu/download/36235491/Laporan_ri skesdas_2010.pdf

[4] Badan Penelitian dan Pengembangan Kesehatan. Hasil Utama Riskesdas 2018 [Internet]. 2018 [cited 2018 Dec 3]. Available from: http://www.depkes.go.id/resources/download/infoterkini/materi_rakorpop_2018/Hasil Riskesdas 2018.pdf

[5] Zhou D, Xi B, Zhao M, Wang L, Veeranki SP. Uncontrolled hypertension increases risk of all-cause and cardiovascular disease mortality in US adults: the NHANES III Linked Mortality Study. Sci Rep [Internet]. 2018 Dec 20 [cited 2019 Mar 22];8(1):9418. Available from: http://www.nature.com/articles/s41598-018-27377-2

[6] Ikeda N, Sapienza D, Guerrero R, Aekplakorn W, Naghavi M, Mokdad AH, et al. Control of hypertension with medication: a comparative analysis of national surveys in 20 countries. Bull World Heal Organ [Internet]. 2014 [cited 2019 Mar 22]; Available from: https://www.who.int/bulletin/volumes/92/1/13121954.pdf? ua $=1$

[7] Abdul-Razak S, Daher AM, Ramli AS, Ariffin F, Mazapuspavina Y, Ambigga KS, et al. Prevalence, awareness, treatment, control and socio demographic determinants of hypertension in Malaysian adults. BMC Public Health [Internet]. 2016 [cited 2019 Mar 8]; Available from:https://remotelib.ui.ac.id:2155/docview/1924735428? pq-origsite $=$ summon

[8] Hussain MA, Al Mamun A, Reid C, Huxley RR. Prevalence, awareness, treatment and control of hypertension in Indonesian adults aged $\geq 40$ years: Findings from the Indonesia Family Life Survey (IFLS). PLoS One [Internet]. 2016;11(8):1-16. Available from: http://dx.doi.org/10.1371/journal.pone.0160922

[9] Pradono J et al. Controlled hypertension: a prospective cohort study in Bogor 2011-2016. J Rev Process. 2019;

[10] Sabaka P, Dukat A, Gajdosik J, Bendzala M, Caprnda M, Simko F. The effects of body weight loss and gain on arterial hypertension control: an observational prospective 
[22] Liu, X. et al. Racial/ethnic disparity in the associations of smoking status with uncontrolled hypertension subtypes among hypertensive subjects', PloS one, 2017: 12(8), p. e0182807. doi: 10.1371/journal.pone.0182807.

[11] Riyadina W. Dinamika Perubahan Indeks Massa Tubuh dan Tekanan darah pada Wanita Pasca Menopause di Kota Bogor, tahun 2011 - 2014 (Disertasi). University of Indonesia; 2017.

[12] Riyadina dkk W. Laporan Studi Kohor Faktor Risiko PTM 2018. Jakarta; 2018.

[13] Gee, M. E. et al. Prevalence of, and Barriers to, Preventive Lifestyle Behaviors in Hypertension (from a National Survey of Canadians With Hypertension). J Cardiol, 2012: 109, pp. 570-575. doi: 10.1016/j.amjcard.2011.09.051.

[14] Chow, C. K. et al. Prevalence, Awareness, Treatment, and Control of Hypertension in Rural and Urban Communities in High-, Middle-, and Low-Income Countries, JAMA. American Medical Association. 2013: 310(9), p. 959. doi: 10.1001/jama.2013.184182.

[15] Rivera-andrade A, Luna MA. One-year follow-up changes in weight are associated with changes in blood pressure in young Mexican adults. Public Health. 2014;57(3):276-85.

[16] Decoste, M. et al. Uncontrolled hypertension among black Africans in the city of Brussels: A case-control study, European Review for Medical and Pharmacological Sciences. 2013.

[17] Goverwa, T. P. et al. Uncontrolled hypertension among hypertensive patients on treatment in Lupane District, Zimbabwe, 2012. doi: 10.1186/1756-0500-7-703.

[18] Lee, H. S. et al. Factors associated with control of blood pressure among elderly people diagnosed with hypertension in a rural area of South Korea: The Chungju metabolic disease cohort study (CMC study), Blood Pressure. 2010: 19(1), pp. 31-39. doi: $10.3109 / 08037050903424117$.

[19] Carlsson, A. C. et al. Factors associated with uncontrolled hypertension and cardiovascular risk in hypertensive 60-year-old men and women-a populationbased study, Hypertension Research. 2009: 32(9), pp. 780785. doi: 10.1038/hr.2009.94.

[20] Arden, C. The ESH/ESC guidelines for the management of arterial hypertension, Primary Care Cardiovascular Journal. 2014: 7(2), pp. 85-88. doi: 10.3132/pccj.2014.011.

[21] Mats Börjesson, Aron Onerup, Stefan Lundqvist, B. D. Physical activity and exercise lower blood pressure in individuals with hypertension: narrative review of $27 \mathrm{RCTs}$, (October), pp. 2005-2006. Jiang SZ, Lu W, Zong XF, Ruan HY, Liu Y. Obesity and hypertension. Exp Ther Med. 2016;12(4):2395-9. 